\title{
Avaliação do paciente em reabilitação cardiopulmonar quanto ao relacionamento profissional e paciente
}

Fernando Behling

Paula Zeni
CADERNO DE RESUMOS Fisisenectus. Unochapecó Ano 1 - Edição especial - 2013 p. 119

Fernando Behling, acadêmico do curso de Fisioterapia, Universidade Comunitária da Região de Chapecó (Unochapecó), fernandobehling@unochapeco.edu.br

\section{Resumo}

Introdução: Estados de excitação emocional, perturbadores da homeostase orgânica, que geram respostas adaptativas sistêmicas, podem caracterizar a definição do termo estresse, cujos efeitos encontram-se em todos os sistemas orgânicos. A participação do estresse mental nos distúrbios patológicos que envolvem o sistema cardiovascular é bem documentada por pesquisas permanentes, sendo a doença isquêmica do miocárdio e a doença arterial coronariana as principais em acometimento cardíaco e sistêmico relacionado aos quadros de estresse. 0 aumento da prevalência de doenças cardiovasculares em todo o mundo colocou estas afecções do aparelho circulatório como as primeiras em incidência de causas de morte em relação às demais, gerando enormes gastos em saúde pública. Ainda são escassos estudos que propõem-se a investigar o empoderamento do paciente em relação à sua doença/estado de saúde, vinculado ao tratamento. Objetivos: Identificar a avaliação do paciente quanto ao relacionamento profissional de saúde-paciente. Metodologia: Aplicação de questionário elaborado pelos autores. Consiste em 16 questões que exploram a percepção do sujeito em relação a sua situação de saúde e ao relacionamento com o profissional de saúde envolvido no processo de tratamento. O sujeito, que vinha realizando reabilitação cardíaca na Clínica-escola de Fisioterapia da Unochapecó, por 5 meses, tinha de responder se as afirmativas do questionário correspondiam como pouco, bastante, muito, totalmente verdadeiro ou totalmente falso. Resultados: Catorze pacientes avaliados, de um total de 22 que contemplam o grupo. Os principais achados destacam que: 7 pacientes (50\%) não conhecem satisfatoriamente seu estado de saúde; 7 (50\%) sentem-se tristes desde que constatada sua doença; 6 (42,8\%) não conseguem compreender plenamente as causas da sua doença/condição; todos os pesquisados se sentem minimamente tranquilos, apesar da sua condição de saúde; e $10(71,4 \%)$ dos pacientes entrevistados afirmaram que se sentem capazes de contribuir com os cuidados da sua saúde, porém não sabem como fazê-lo; e 6 (42,8\%) afirmam que nem sempre os profissionais de saúde envolvidos em seu tratamento preocupavam-se em explicar o que acontecia. Considerações finais: Os pacientes se sentem tranquilos em relação ao seu estado de saúde, o que não significa que há pleno esclarecimento quanto à causa da sua condição, da sua capacidade de contribuir para a melhora do seu estado de saúde, os profissionais de saúde que participam do tratamento nem sempre buscaram esclarecer o paciente quanto à sua situação. Esses achados podem influenciar nos níveis de estresse e, por conseguinte, limitar o propósito da reabilitação e da atenção à saúde.

\section{Palavras-chave}

Estresse psicológico. Fisioterapia. Indicadores básicos de saúde.

Fonte de Financiamento: Fundo de apoio à pesquisa da Unochapecó (PIBIC/FAPE). 